\title{
Comparison and quantitation of Ia antigen expression on cultured macroglia and ameboid microglia from Lewis rat cerebral cortex: analyses and implications
}

\author{
Atsushi Sasaki ${ }^{1}$, Steven W. Levison ${ }^{3}$ and Jenny P.-Y. Ting ${ }^{1,2,3}$ \\ ${ }^{\prime}$ Lineberger Cancer Center, ${ }^{2}$ Department of Microbiology - Immunology, and ${ }^{3}$ Curriculum in Neurobiology, \\ University of North Carolina, Chapel Hill, NC 27599, U.S.A.
}

(Received 15 March 1989)

(Revised, received 4 May 1989)

(Accepted 4 May 1989)

Key words: Ia antigen; Interferon- $\gamma$; Cytofluorometry; Astrocyte, type 1 and type 2; Oligodendrocyte; Ameboid microglia

\section{Summary}

We isolated two subclasses of astrocytes, oligodendrocytes and ameboid microglia from Lewis rat cerebral cortex and analyzed Ia antigen expression on each glial cell type by immunofluorescent microscopy and cytofluorometry. All of these expressed little or no Ia without interferon- $\gamma$ (IFN- $\gamma$ ) treatment. Following IFN- $\gamma$ treatment, Ia expression was observed on a majority $(\sim 80 \%)$ of ameboid microglia, on half $(-55 \%)$ of the type 1 astrocytes, on a small number $(\sim 7 \%)$ of type 2 astrocytes, but not on oligodendrocytes. These findings suggest that the type 1 astrocyte and microglia may play more predominant roles in Ia-related, immune-mediated intracerebral lesions although the type 2 astrocytes may also be involved.

\section{Introduction}

The products of class II major histocompatibility complex, $i$ mmune response associated (Ia) antigen, play a critical role in the elicitation of an immune response. Cells displaying Ia antigens are present in various organs. In normal brain, rare Ia-positive cells have been detected in the white matter (Natali et al., 1981; Ting et al., 1981;

Address for correspondence: Jenny P.-Y. Ting, Ph.D., Lineberger Cancer Research Center, CB 7295, Rm 209, School of Medicine, The University of North Carolina, Chapel Hill, NC 27599-7295, U.S.A.
Nixon et al., 1982; Hauser et al., 1983; de Tribolet et al., 1984; Hayes et al., 1987). In abnormalities, Ia antigen expressing astrocytes have been demonstrated in brain lesions of multiple sclerosis (Traugott et al., 1985; Hofman et al., 1986), murine experimental allergic encephalomyelitis (Sakai et al., 1986), and virus-induced demyelination (Rodriguez et al., 1987). Similarly, Ia-bearing microglia have been observed in a large number of neurologic diseases such as Alzheimer's, Parkinson's, Pick's and Huntington's disease (McGeer et al., 1988a, b). In culture, interferon- $\gamma(\mathrm{IFN}-\gamma)$ has been shown to induce Ia antigen on a portion of astrocytes (Wong et al., 1984) as well as microglia (Frei et al., 1987; Suzumura et al., 1987). Both cell 
types were able to present antigen to antigenspecific $T$ cell lines upon expression of Ia (Fontana et al., 1984; Takiguchi and Frelinger, 1986; Frei et al., 1987). The purpose of this report is to examine two remaining issues: First, do subpopulations of astrocytes express different levels of Ia antigens? Second, do microglia and astrocytes respond equally to IFN- $\gamma$ treatment?

Recent in vitro studies of rat glial development document the existence of subsets of rat astrocytes. These astroglial subtypes, termed type 1 and type 2, are thought to correspond to protoplasmic (type 1) and fibrous (type 2) astrocytes found in vivo (Miller and Raff, 1984). The protoplasmic astrocytes are located mainly in the gray matter, whereas the fibrous astrocytes are found in the white matter, and are also involved in the formation of the blood-brain barrier. The connotation of these differences is that different subsets of astrocytes may play different functional roles. Although it is clear that IFN- $\gamma$-treated astrocytes express Ia antigen, it is unclear if both astrocyte subsets can express this antigen. This information is important to assess if subsets of astrocytes can participate in immune responses in the central nervous system (CNS). For example, the expression of Ia antigen by fibrous astrocytes which are mainly found in the white matter may be relevant to disease processes which are immune-mediated, and which are restricted to the white matter.

In addition to astrocytes, brain phagocytes also referred to as ameboid microglia or macrophage/ microglia (Giulian and Baker, 1986; Suzumura et al., 1987; Hayes et al., 1988) can be induced to express Ia. Phenotypically, these cultured cells resembled macrophages. They express Ia antigens after stimulation with IFN- $\gamma$ (Suzumura et al., 1987) and they function as antigen-presenting cells (Frei et al., 1987). In a number of neurologic diseases, $\mathrm{Ia}^{+}$microglia but not $\mathrm{Ia}^{+}$astrocytes were found (McGeer, 1988b). Even in CNS diseases where $\mathrm{Ia}^{+}$astrocytes have been observed, they were sparse (Wekerle et al., 1986). These observations render it important to compare the capacity of microglia vs. astrocytes to express Ia.

In this report we separated type 1 and type 2 astrocytes, microglia and oligodendrocytes from a rat mixed glial cell culture from cerebral cortex. Ia antigen expression on each type of glial cell before and after IFN- $\gamma$ treatment was examined using immunofluorescence microscopy and/or immunofluorescence flow cytometry. The order of Ia levels expressed by different glial cells after IFN- $\gamma$ induction was: microglia $>$ type 1 astrocytes $\gg$ type 2 astrocytes. Oligodendrocytes were not induced to express Ia.

\section{Materials and methods}

\section{Primary glial cultures}

Cultures were prepared essentially as described by McCarthy and de Vellis (1978). The cerebral cortical tissue was collected from newborn Lewis rats ( 2 days postnatal at the latest). Cells were plated into T-flasks $\left(75 \mathrm{~cm}^{2}\right.$ area) at approximately $1.8 \times 10^{5}$ cells $/ \mathrm{cm}^{2}$. Mixed glial cultures were grown in Eagle's basal medium with Earle's salts, $2 \mathrm{mM}$ L-glutamine and sodium bicarbonate plus $0.6 \%$ glucose, $50 \mathrm{IU} / \mathrm{ml}$ penicillin and 50 $\mu \mathrm{g} / \mathrm{ml}$ streptomycin (supplemented BME) plus $10 \%$ fetal calf serum (FCS) (Gibco). The medium was changed after the first 3 days and 3 times a week thereafter.

Separation of ameboid microglia, typé 1 and 2 astrocytes and oligodendrocytes

The methods used to isolate the different glial cells types were those of McCarthy and de Vellis (1980) and Giulian and Baker (1986). A schematic diagram of the separation protocol is shown in Fig. 1. Following approximately 14 days of growth, confluent mixed glial cell cultures were shaken at $260 \mathrm{rpm}, 37^{\circ} \mathrm{C}$ for $1 \mathrm{~h}$. The nonadherent cells which contained the microglia were collected and plated onto $9 \times 9 \mathrm{~mm}$ glass coverslips in 12-well plates (Costar), or into 12-well plates. They were incubated at $37^{\circ} \mathrm{C}$ for $1 \mathrm{~h}$ to allow adherence to the coverslips or plates. Nonadherent cells in the medium were removed and the wells were further washed twice to remove remaining nonadherent cells. The adherent cells were re-fed with supplemented BME plus 10\% FCS and used as ameboid microglia-enriched cultures.

For the isolation of macroglia which include type 1 and type 2 astrocytes, and oligodendrocytes, adherent cells from the initial shake were further shaken for $18 \mathrm{~h}\left(260 \mathrm{rpm}, 37^{\circ} \mathrm{C}\right)$ on an 
Preparation of glial

subpopulations in vitro

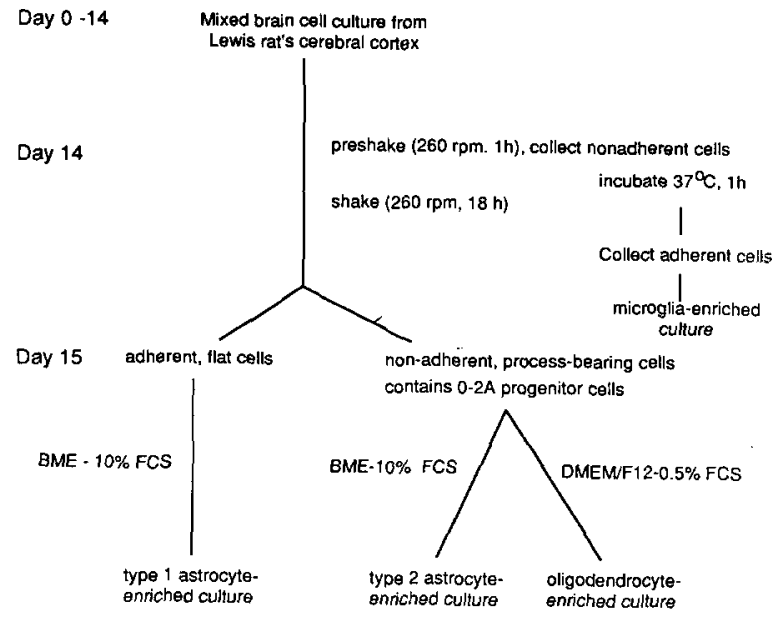

Fig. 1. A schematic representation of the separation protocol for type 1, type 2 astrocytes, microglia, and oligodendrocytes.

orbital shaker. Process-bearing (P-B) cells which were loosened by shaking were plated onto glass coverslips previously coated with poly-D-lysine (10 $\mu \mathrm{g} / \mathrm{ml})$ in 12-well plates at a density of $1-2 \times 10^{4}$ cells $/ \mathrm{cm}^{2}$ or in T-flasks $\left(75 \mathrm{~cm}^{2}\right)$ at a similar density. After 1 day of subculture in supplemented BME plus 10\% FCS to allow cell attachment to the substratum, the medium was replaced with either a $1: 1$ mixture of Dulbecco's modified Eagle medium containing $4.5 \mathrm{~g} / 1$ glucose and Ham's F12 medium (DMEM/F12) plus 0.5\% FCS to enrich for oligodendrocytes or with fresh $\mathrm{BME}$ plus 10\% FCS to enrich for type 2 astrocytes (Raff et al., 1983b).

After the P-B cells were harvested, the remaining adherent flat cells were harvested by treatment with trypsin $(0.25 \%, 5 \mathrm{~min})$, resuspended in supplemented BME plus 10\% FCS, and replated on poly-D-lysine-coated coverslips in 12 -well plates at a density of approximately $2.5 \times 10^{3}$ cells $/ \mathrm{cm}^{2}$ or in T-flasks at a density of $1.3-1.6 \times 10^{4}$ cells $/ \mathrm{cm}^{2}$. This population contained mostly type 1 astrocytes.

\section{Recombinant rat IFN- $\gamma(r I F N-\gamma)$}

Stock solutions of rIFN- $\gamma$ (Amgen, Thousand Oaks, CA, U.S.A.) were diluted to a concentration of $2 \times 10^{4} \mathrm{U} / \mathrm{ml}$ in phosphate-buffered saline (PBS) (pH 8.5) with $2 \%$ FCS and stored at $-70^{\circ} \mathrm{C}$. Serial dilutions were made in culture medium. Cells were usually treated with rIFN- $\gamma$ (20-50 $\mathrm{U} / \mathrm{ml}$ ) for 2 days prior to assaying the effects of IFN- $\gamma$.

\section{Antibodies}

For membrane la antigen staining, a monoclonal mouse IgG1 antibody against rat Ia (OX-6; Serotec, Oxford, U.K.) was used. Glial fibrillary acidic protein (GFAP), a marker for astrocytes, was identified by rabbit immunoglobulins to bovine GFAP (Dakopatts, Denmark). An IgG3 mouse monoclonal antibody to galactocerebroside (GC; generously supplied by Dr. B. Ranscht) was used to identify oligodendroglia. $A b R_{24}$, the GD3-specific mouse monoclonal antibody (IgG3) and A2B5 mouse monoclonal antibody ( $\operatorname{IgM})$ were used as markers for type 2 astrocytes $\left(A \mathrm{BR}_{24}\right.$ was generously supplied by Dr. K. Lloyd and A2B5 $\mathrm{Ab}$ was obtained from the ATCC). The monoclonal IgG2a antibody against rat CR3 complement receptor OX-42 (Serotec, Oxford, U.K.) was used to identify ameboid microglia. Both tetramethylrhodamine isothiocyanate (TRITC)-labeled goat anti-mouse IgG1 and fluorescence isothiocyanate (FITC)-labeled goat anti-mouse IgG3 were purchased from Southern Biotechnology Associates (Birmingham, AL, U.S.A.). FITC-conjugated goat anti-rabbit IgG, FITC-conjugated anti-mouse IgM, FITC-conjugated goat anti-mouse IgG and TRITC-conjugated goat anti-mouse IgG were purchased from Cappel (West Chester, PA, U.S.A.).

\section{Immunofluorescence microscopy}

Cells grown on coverslips were rinsed with $\mathrm{BME}$ (pH 7.3) with $20 \mathrm{mM}$ Hepes (BME-Hepes), and stained by double-label indirect immunofluorescence. The sequence for double staining with Iaspecific plus GFAP-specific antibodies was as follows: (1) incubation with the Ia-specific $\mathrm{mAb}$ OX-6 (1:100) for $60 \mathrm{~min}$; (2) incubation with TRITC-labeled goat anti-mouse IgG1 $(1: 20)$ for $30 \mathrm{~min}$; (3) fixation with $4 \%$ paraformaldehyde in $0.1 \mathrm{M}$ PBS, pH 7.4 for $10 \mathrm{~min}$, at $4^{\circ} \mathrm{C}$; (4) permeabilization with $0.05 \%$ saponin in BMEHepes plus 10\% FCS for $30 \mathrm{~min}$; (5) incubation with rabbit antiserum against GFAP $(1: 100)$ for 
$30 \mathrm{~min}$; (6) incubation with FITC-conjugated $\mathrm{F}\left(\mathrm{ab}^{\prime}\right)_{2}$ fragments of goat anti-rabbit IgG $(1: 200)$ for $30 \mathrm{~min}$. Steps 1,2 and 3 were followed by three rinses with BME-Hepes plus $10 \%$ FCS, and steps 5, 6 with three rinses of BME-Hepes plus $10 \%$ FCS containing $0.05 \%$ saponin.

Double staining with combinations of antibodies against Ia/GC, Ia/GD3, and Ia/A2B5 was performed as follows: (1) incubation (60 min) with OX-6 mAb (1:100) plus GC-specific mAb (1:100), or GD3-specific mAb $(1: 100)$ or A2B5 mAb (1:2); (2) incubation (30 min) with TRITClabeled goat anti-mouse IgG1 $(1: 20)$ plus FITClabeled goat anti-mouse IgG3 (1:20, for GCspecific and GD3-specific mAbs) or FITC-labeled goat anti-mouse $\operatorname{IgM}(1: 50$, for A2B5 mAb); (3) fixation with $4 \%$ paraformaldehyde in $0.1 \mathrm{M}$ PBS pH $7.4\left(10 \mathrm{~min}, 4^{\circ} \mathrm{C}\right)$. Between each step the coverslips were rinsed 3 times with BME-Hepes plus $10 \%$ FCS. All the steps for double staining were done at room temperature except for the fixation step. Primary antibodies were omitted in negative controls.

Double staining of ameboid microglia with OX-6 or OX-42 monoclonal antibodies and GFAP-specific antibody was performed essentially as described above. However, the microgliaenriched cultures were pre-incubated $(10 \mathrm{~min})$ with $50 \%$ normal goat serum (NGS) plus $0.1 \% \mathrm{NaN}_{3}$ to block non-specific binding to the Fc receptor. In addition, both the primary antibodies (OX-6, OX42) and TRITC-labeled goat anti-mouse IgG were diluted in $50 \%$ NGS plus $0.1 \% \mathrm{NaN}_{3}$.

After incubations with the antibodies, coverslips were placed on microscope slides, covered with PBS, pH 7.8: glycerol $(1: 1)$, overlaid with $60 \times 24 \mathrm{~mm}$ glass coverslips and sealed with fingernail polish. Stained cells were viewed with phase-contrast and epifluorescence optics using a Zeiss inverted photomicroscope. To determine the percent of positively stained cells, at least 200 total cells were counted in non-overlapping fields from two coverslips in one experiment, using a $\times 40$ or $\times 63$ objective lens and a $\times 10$ eye piece. Before conducting double-labeling study, it was confirmed by immunofluorescent analysis that the secondary antibodies showed no crossreaction, i.e., OX-6 mAb did not crossreact with FITC-labeled goat anti-mouse IgG3 or IgM; GD3-specific,
A2B5- or GC-specific mAbs did not crossreact with TRITC-labeled goat anti-mouse IgG1.

\section{Flow cytometric analysis}

Type 1, 2 astrocytes and ameboid microglia were analyzed using flow cytometry to quantitate their capacity to express Ia antigens. The cells were collected with $0.25 \%$ trypsin (for astrocytes) or a rubber policeman (for microglia), and then incubated for $45-60 \mathrm{~min}$ with OX-6 mAb diluted $1: 100$, followed by a $30 \mathrm{~min}$ incubation with goat anti-mouse IgG conjugated to FITC $(1: 20)$ at $4^{\circ} \mathrm{C}$. Afterwards, cells were washed and incubated with propidium iodide $(5 \mu \mathrm{g} / \mathrm{ml})$ to enable the exclusion of non-viable cells. More than 10000 cells/category were analyzed on a cytofluorometric analyzer (Ortho CytoFluorograf $50 \mathrm{H}$ ).

\section{Results}

Expression of Ia on type 1 astrocytes as determined by fluorescence microscopy

Adherent, flat cells isolated as described in Materials and Methods (also Fig. 1) and subcultured in medium for 5-6 days exhibited a fibroblast-like or polygonal cell morphology under phase-contrast microscopy (Fig. 2A). Ia/GFAP double-labeling staining of flat cells from three experiments showed that $>90 \%$ of the cells were positive for the astrocytic marker, GFAP (Fig. $2 B$ ). We defined these cells as type 1 astrocytes. Ia antigen was not detected on untreated type 1 astrocytes, but upon treatment with rIFN- $\gamma$ (50 $\mathrm{U} / \mathrm{ml}$ ) for 2 days, approximately $55 \%$ of GFAPpositive type 1 astrocytes became la-positive in culture (Fig. $2 C$ ).

\section{Expression of Ia antigens on type 2 astrocytes}

For the isolation of type 2 astrocytes, P-B cells were subcultured in supplemented BME plus $10 \%$ FCS for at least 5 days (see Fig. 1). The inclusion of FCS in the culture medium has been previously shown to induce the cerebral cortical P-B cells to differentiate into type 2 astrocytes (Ingraham and McCarthy, 1989). Determinations from three experiments show that $75-80 \%$ of the P-B cells were GFAP-positive and hence these were likely to be type 2 astrocytes (Fig. $3 A$ and $B$ ). These astro- 

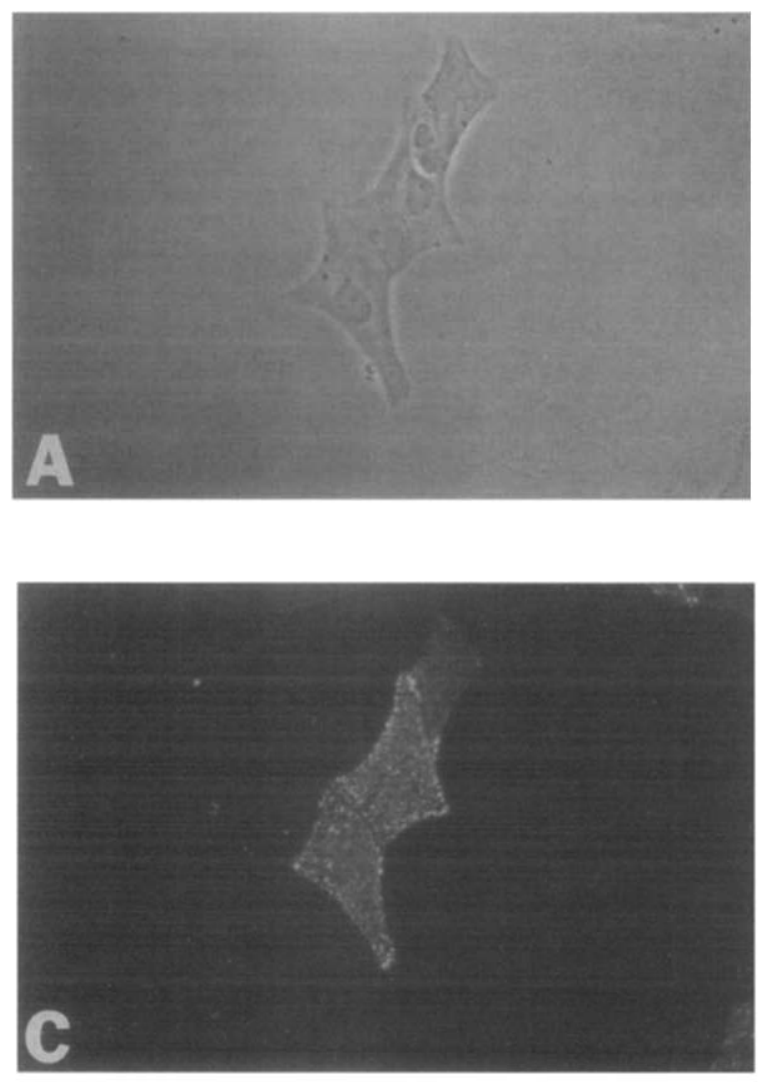

cytes initially identified by P-B morphology and GFAP positivity exhibited no Ia antigen expression in the absence of rIFN- $\gamma$. After treatment with $50 \mathrm{U} / \mathrm{ml}$ of rIFN- $\gamma$ for 2 days, most of these astrocytes were still Ia-negative and only $5 \%$ of them became Ia-positive (Fig. 3C). Among the 5\% of $\mathrm{Ia}^{+} \mathrm{P}-\mathrm{B}$ astrocytes, Ia antigens were found on the surfaces of the small cell body and thin, long processes.

Morphologic criteria alone are insufficient for the characterization of type 2 astrocytes. For the further characterization of Ia expression on type 2 astrocytes, two markers (GD3 and A2B5) that are expressed by type 2 but not type 1 astrocytes were used. R24 monoclonal antibody detects the GD3 disialoglioside (Pukel et al., 1982), and A2B5 antibodies bind to polysialogangliosides (Eisenbarth et al., 1979). Previous studies have shown that $\mathrm{GD}^{-} / \mathrm{A}^{2} \mathrm{~B}^{-} / \mathrm{GFAP}^{+}$cells are type 1 astrocytes while most $\mathrm{GD}^{+} / \mathrm{A} 2 \mathrm{~B} 5^{+} / \mathrm{GFAP}^{+}$cells are type 2 astrocytes (Raff et al., 1983a, b; Goldman et al., 1986). It was confirmed here that many $(55-75 \%)$

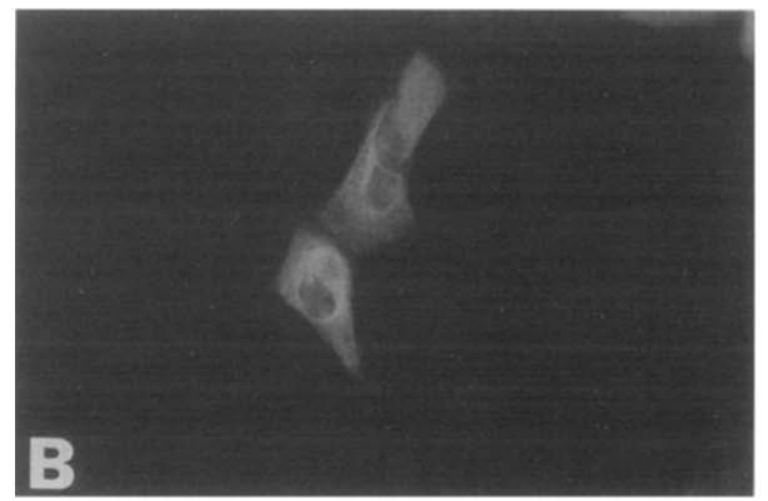

Fig. 2. Ia antigen induction on type 1 astrocytes. The adherent cell subcultures, enriched for type 1 astrocytes, were incubated with $50 \mathrm{U} / \mathrm{ml}$ of rIFN- $\gamma$ for 2 days. These cells were double stained with Ia-specific $\mathrm{mAb}$ and TRITC-conjugated secondary antibodies $(C)$ or GFAP-specific antiserum and FITC-conjugated secondary antibodies $(B) .(A)$ is a phase-contrast micrograph of the same field shown in $(B)$ and (C). Two Ia-positive polygonal cells were detected among three GFAP-positive cells. $(\times 280)$

P-B cells were stained with both GD3-specific and A2B5 mAbs in untreated or rIFN- $\gamma$-treated cultures (Fig. $3 E$ and $H$ ). Ia/GD3 and Ia/A2B5 double-labeling studies showed that $7-9 \%$ of $\mathrm{GD}^{+}$or $\mathrm{A} 2 \mathrm{~B} 5^{+}$cells which are of process-bearing morphology became Ia-positive in the rIFN- $\gamma$ treated cultures (Fig. $3 D-I$ ). Triple staining was not used to examine the simultaneous expression of Ia with GFAP and A2B5 or GD3 because of technical difficulties. However, since these cells had a process-bearing morphology, and exhibited the markers of type 2 astrocytes as well as Ia antigens, we concluded that Ia antigens are expressed by a small number of type 2 astrocytes upon IFN- $\gamma$ stimulation.

\section{Expression of Ia antigens on ameboid microglia}

The majority of the cells in the ameboid microglia-enriched culture showed a circular shape and sometimes vacuolated cytoplasm, with diameters ranging from 20 to $40 \mu \mathrm{m}$ (Fig. $4 A$ and $C$ ). Immunofluorescent staining showed that they were 
OX-42-positive (88-97\%, Fig. 4B) and GFAPnegative (data not shown). In addition, $>95 \%$ of the cells bound TRITC-labeled Ig in the absence of unlabeled blocking serum, presumably via their
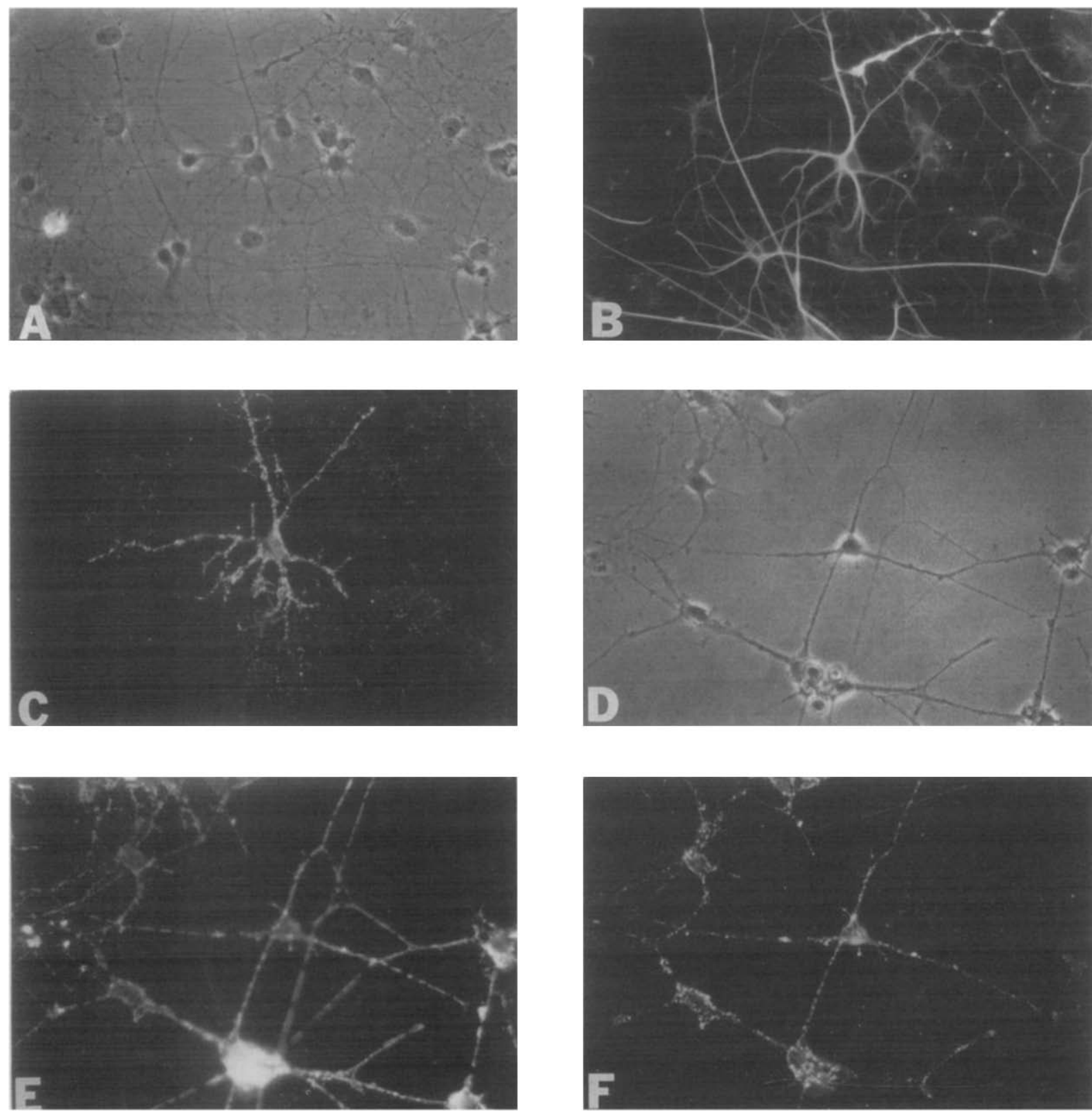

Fig. 3. Ia antigen induction on type 2 astrocytes. Non-adherent, process-bearing cells were subcultured in supplemented BME plus $10 \%$ FCS for 3-5 days to enrich for type 2 astrocytes, and then exposed to $50 \mathrm{U} / \mathrm{ml}$ of rIFN- $\gamma$ for 2 days. These cells were double-labeled for GFAP and Ia ( $B$ and $C$ respectively), GD3 and Ia ( $E$ and $F$ ) or A2B5 and Ia $(H$ and $I) .(A),(D)$ and $(G)$ are phase-contrast micrographs. Only one process-bearing cell was double-stained for GFAP ${ }^{+} / \mathrm{Ia}^{+}$in the field $(A-\mathrm{C} \times 280)$. At least three cells were double-stained $\left(\mathrm{GD}^{+} / \mathrm{Ia}^{+}\right)$in the field $(D-F \times 280)$. One $\mathrm{A} 2 \mathrm{~B}^{+} / \mathrm{la}^{+}$process-bearing cell was seen in the field

$$
(G-I \times 440) \text {. }
$$



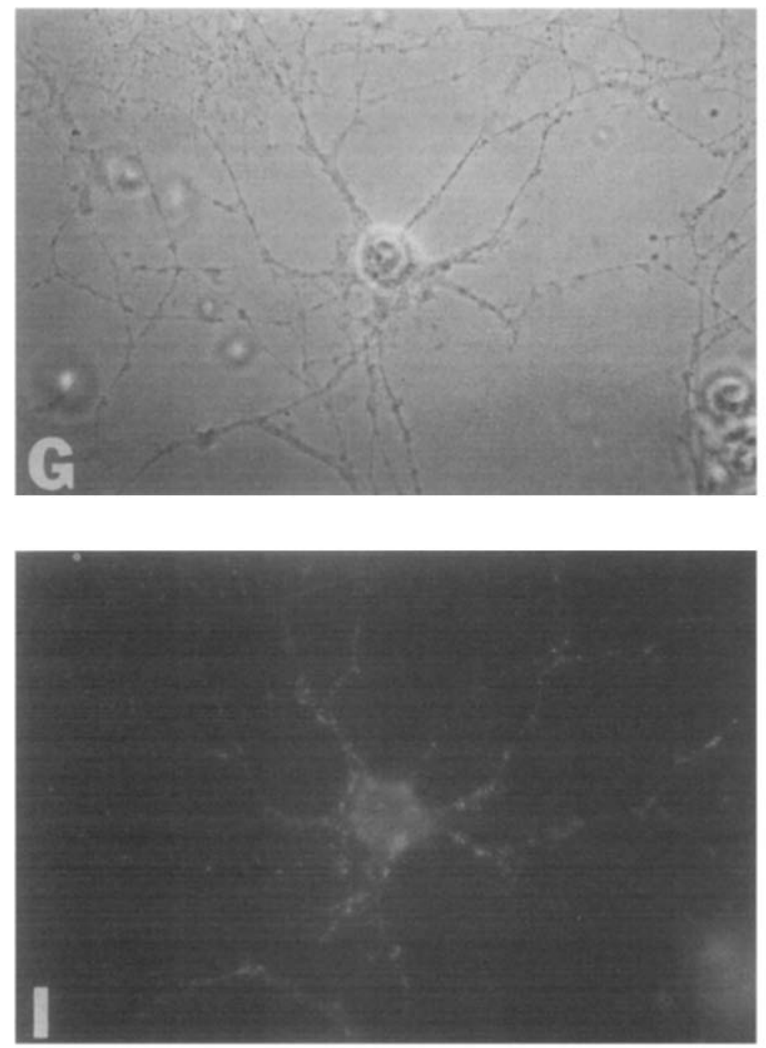

mouse serum or normal rabbit serum. In the absence of rIFN- $\gamma$ only a small number $(2 \%)$ of cells weakly expressed la antigen. In contrast, following exposure to rIFN- $\gamma(50 \mathrm{U} / \mathrm{ml})$ for 2 days, the majority ( $82 \%$ ) of cells were Ia-positive (Fig. $4 D$ ).

\section{Expression of la antigens on oligodendrocytes}

For enriched cultures of oligodendrocytes, P-B cells subcultured for 5-6 days in DMEM/F12 plus $0.5 \%$ FCS were used. This culturing condition results in the enrichment of oligodendrocytes. P-B cells, which morphologically had thick, webby process or membranous expansions and were GC-positive, were identified as oligodendrocytes (Fig. 5). Using these criteria nearly $50 \%$ of the cells in this culture were oligodendrocytes. Ia antigen was not detected on either untreated or rIFN$\gamma$-treated, GC-expressing oligodendrocytes in double-staining experiments (Fig. 5). This result is in accord with previous reports of mouse oligodendrocytes (Wong et al., 1984; Suzumura et al.,

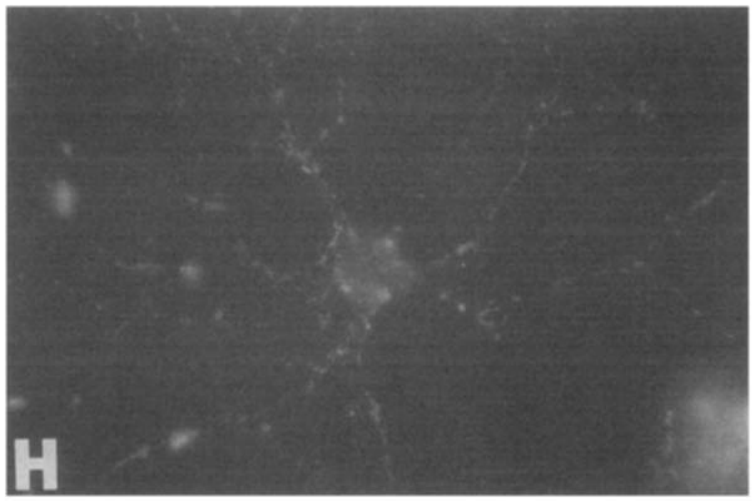

Fig. 3 (continued).

1986) and rat oligodendrocytes (Calder et al., 1988).

Double staining of rIFN- $\gamma$-treated culture with Ia-specific and GC-specific mAbs showed that a few GC-negative cells with a bipolar morphology were Ia-positive (Fig. 5). These bipolar cells may represent $\mathrm{O}-2 \mathrm{~A}$ progenitors. During the preparation of this report, $\mathrm{O}-2 \mathrm{~A}$ progenitors have been shown to express Ia following IFN- $\gamma$ treatment (Calder et al., 1988).

\section{Flow cytometry}

Flow cytometric analysis was performed in parallel to quantitate the percent of Ia expressing type 1, 2 astrocytes and microglia (Tables 1 and 2 ). Among the adherent, flat cells, $>90 \%$ of the cells appeared to be typical type 1 astrocytes. Therefore, this population was analyzed by cytometry without further gating of selective population. In agreement with the fluorescence microscopy, untreated cells do not express la while 

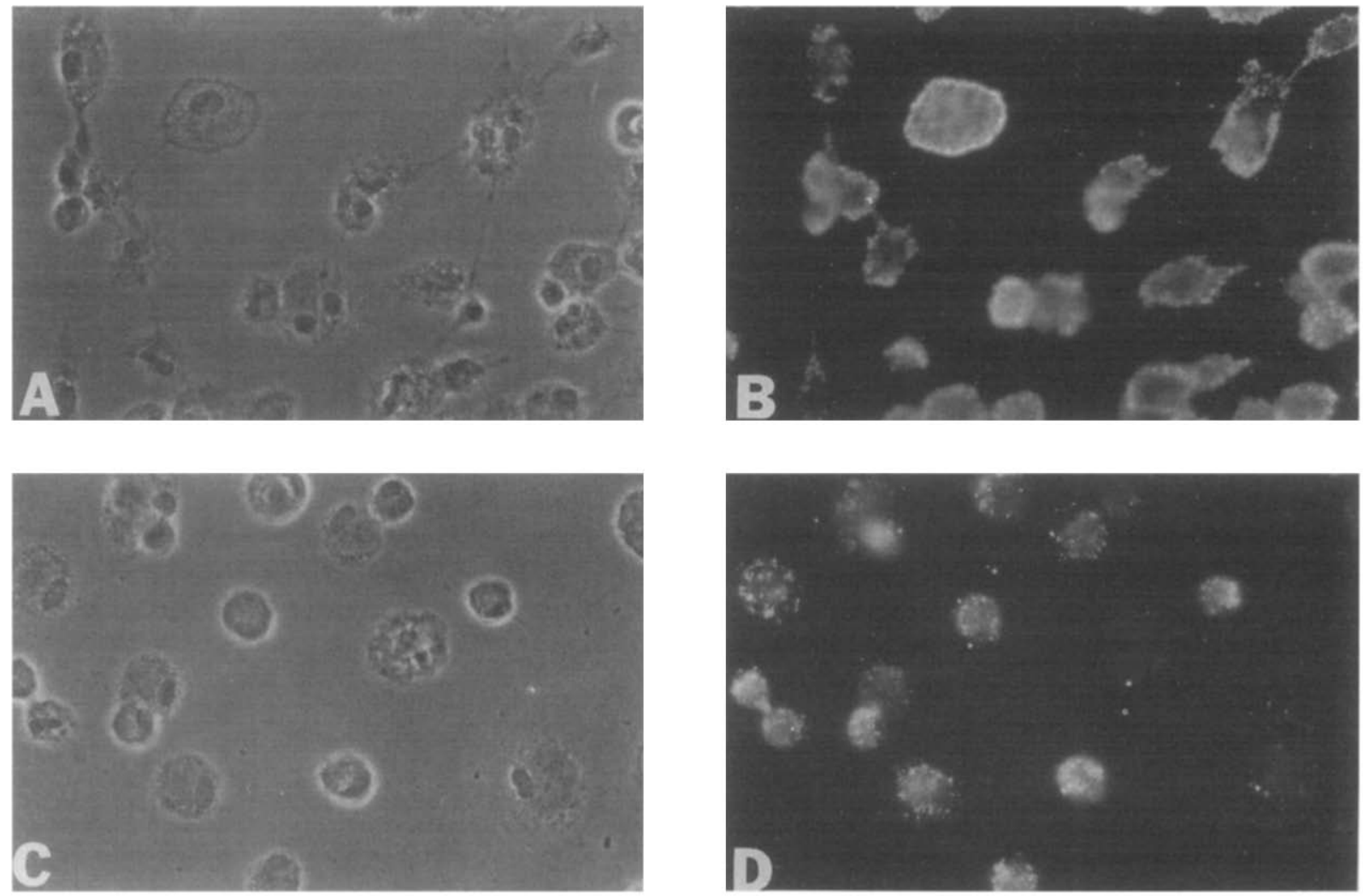

Fig. 4. Ia antigen induction on ameboid microglia. Following exposure to rIFN- $\gamma(50 \mathrm{U} / \mathrm{ml}, 2$ days), cells were stained with monoclonal antibodies against CR3 complement receptor $(B)$ or Ia $(D) .(A)$ and $(C)$ are phase-contrast micrographs of the same field shown in $(B)$ and $(D)$, respectively. Virtually all the cells in the preparation express the CR 3 complement receptor. Most of the ameboid microglia were Ia-positive. $(\times 280)$

$-55 \%$ of rIFN- $\gamma$-treated cells express Ia antigens.

In contrast to the type 1 cells, immunocytochemical study of P-B astrocyte culture showed that (1) the purity of type 2 astrocytes in the cultures was lower $(\sim 80 \%)$ than that of enriched type 1 astrocytes, (2) contaminations of a small number of type 1 astrocytes and ameboid microglia-like cells were found in enriched astrocyte type 2 cultures, and these cells could be induced to express Ia antigen by rIFN- $\gamma$. These caveats necessitated further manipulations for the flow cytometric analysis. By microscopic analysis, it was apparent that the type 2 astrocytes were smaller than both the type 1 astrocytes and microglia-like cells. Therefore, the gate window was set to select for smaller cells to enrich for GD3-positive cells. It was empirically determined that at a gate window of $5-12 \mu \mathrm{m}, 93 \%$ of the cells in this window were GD3-positive. This enrichment of GD3-positive cells supports our contention that type 2 astrocytes are smaller than type 1 astrocytes or microglia. Analysis of Ia expression on this population shows that untreated type 2 astrocytes do not express Ia, while approximately $7 \%$ of rIFN- $\gamma$-treated type 2 astrocytes express Ia. This is in excellent agreement with the microscopic studies (Fig. 3). It also underscores the importance of the microscopic studies, because contaminating $\mathrm{Ia}^{+}$cells are better differentiated upon microscopic examination.

Comparatively, type 1 and 2 astrocyte cultures treated for 2 days with $50 \mathrm{U} / \mathrm{ml} \mathrm{rlFN- \gamma}$ were distinctly different with respect to Ia induction by rIFN- $\gamma$ as determined by cytofluorometric analysis (Table 1). There were 7 times more $\mathrm{Ia}^{+}$type 1 astrocytes than type 2 astrocytes. Also, Ia-positive 

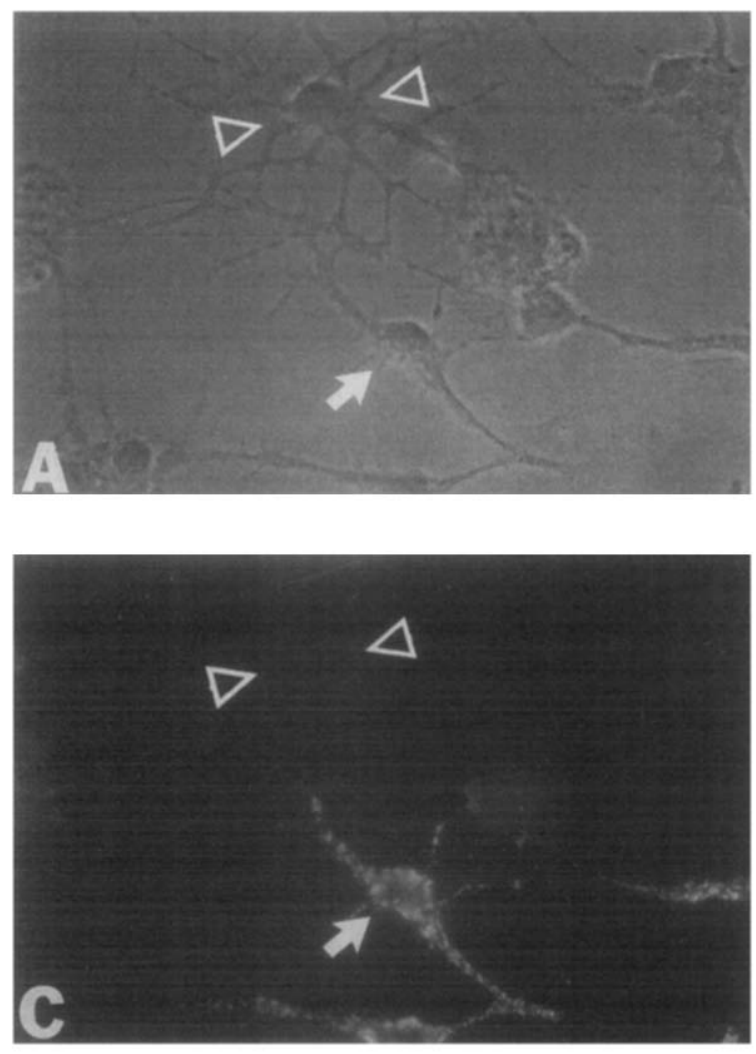

type 1 astrocytes exhibited higher mean fluorescence intensity (MFI) than type 2 astrocytes. In one representative experiment, the MFI of all

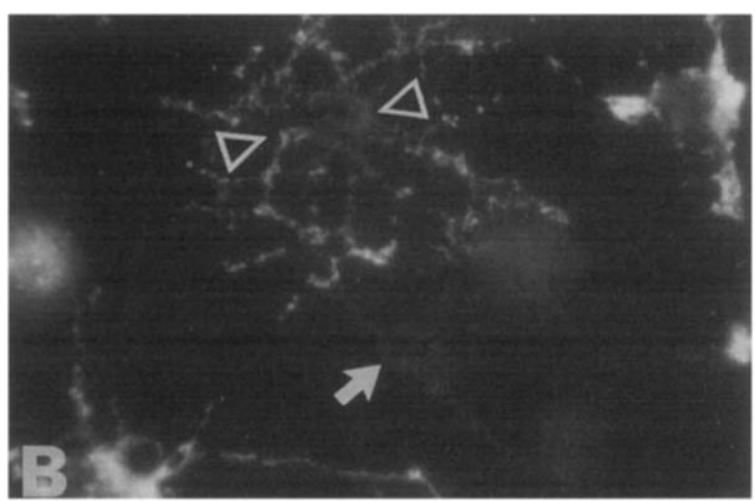

Fig. 5. Ia antigen induction on oligodendrocytes. Oligodendrocyte-enriched subcultures maintained in DMEM/F12 plus $0.5 \%$ FCS were incubated with $50 \mathrm{U} / \mathrm{ml}$ of rIFN- $\gamma$ for 2 days. Photomicrograph of the same field viewed with phase-contrast optics $(A)$ and optics for GC-specific plus FITC-conjugated secondary antibodies $(B)$ and Ia-specific plus TRITC-conjugated secondary antibodies $(C)$ are shown. GCpositive oligodendrocytes with typical web-like process did not express la antigen on their surface (arrowhead). Note that a GC-negative bipolar cell was stained with anti-Ia mAb (arrow). $(\times 440)$

IFN- $\gamma$-treated type 1 astrocytes was 203.6, and the MFI of Ia-positive cells alone in this sample was 328.4. In contrast, the MFI of IFN- $\gamma$-treated type

\section{TABLE 1}

\section{FLOW CYTOMETRIC ANALYSIS OF Ia ANTIGEN EXPRESSION ON TYPE 1 AND TYPE 2 ASTROCYTES}

Type 1 astrocytes and type 2 astrocytes were isolated as depicted in Fig. 1 and were treated with various doses of rIFN- $\gamma$ for 48 h. Cultures were then stained for Ia by indirect immunocytochemistry and analyzed by flow cytometry. In the negative control, primary antibody was omitted. The percentage of Ia expressing cells for type 1 astrocyte is the mean from six experiments, while that for type 2 astrocyte is the mean from two experiments. The mean fluorescence intensity which is determined by channel number $1-1000$ is from a representative experiment and is the intensity of all cells (see Results).

\begin{tabular}{|c|c|c|c|c|}
\hline & \multicolumn{2}{|l|}{ Type 1 astrocyte } & \multicolumn{2}{|l|}{ Type 2 astrocyte } \\
\hline & $\begin{array}{l}\text { Ia expressing } \\
\text { cells } \pm S D(\%)\end{array}$ & $\begin{array}{l}\text { Mean fluorescence } \\
\text { intensity }\end{array}$ & $\begin{array}{l}\text { Ia expressing } \\
\text { cells } \pm \mathrm{SD}(\%)\end{array}$ & $\begin{array}{l}\text { Mean fluorescence } \\
\text { intensity }\end{array}$ \\
\hline \multicolumn{5}{|c|}{ rIFN- $\gamma$ (units $/ \mathrm{ml}$ ) } \\
\hline 0 & $1.0 \pm 0.6$ & 23.7 & $0.5 \pm 0.4$ & 13.7 \\
\hline 20 & $35.3 \pm 7.2$ & ND & ND & ND \\
\hline 50 & $54.2 \pm 9.6$ & 203.6 & $6.8 \pm 2.2$ & 26.1 \\
\hline \multicolumn{5}{|c|}{$\begin{array}{l}\text { Controls (units/ml) } \\
\text { (secondary antibody only) }\end{array}$} \\
\hline 50 & $1.9 \pm 1.3$ & 37.4 & $0.1 \pm 0$ & 14.5 \\
\hline
\end{tabular}

$\mathrm{SD}=$ standard deviation; ND $=$ not determined. 
TABLE 2

FLOW CYTOMETRIC ANALYSIS OF Ia ANTIGEN EXPRESSION ON TYPE 1 ASTROCYTE AND AMEBOID MICROGLIA

Type 1 astrocytes and ameboid microglia were isolated as depicted in Fig. 1 and were treated with 50 units $/ \mathrm{ml}$ of rIFN- $\gamma$ for $48 \mathrm{~h}$. Cultures were then stained for Ia by indirect immunocytochemistry and analyzed by flow cytometry. In the negative control, primary antibody was omitted. The data is from a representative experiment and the mean fluorescence intensity (channel number) is the intensity of all cells (see Results).

\begin{tabular}{|c|c|c|c|c|}
\hline & \multicolumn{2}{|c|}{ Type 1 astrocyte } & \multicolumn{2}{|c|}{ Ameboid microglia } \\
\hline & $\begin{array}{l}\text { Ia } \\
\text { expressing } \\
\text { cells }(\%)\end{array}$ & $\begin{array}{l}\text { Mean } \\
\text { fluorescence } \\
\text { intensity }\end{array}$ & $\begin{array}{l}\text { Ia } \\
\text { expressing } \\
\text { cells }(\%)\end{array}$ & $\begin{array}{l}\text { Mean } \\
\text { fluorescence } \\
\text { intensity }\end{array}$ \\
\hline \multicolumn{5}{|c|}{ IIFN- $\gamma$ (units $/ \mathrm{ml}$ ) } \\
\hline 0 & 2.2 & 44.9 & 4.0 & 46.6 \\
\hline 50 & 62.5 & 231.0 & 80.4 & 215.4 \\
\hline \multicolumn{5}{|c|}{$\begin{array}{l}\text { Controls (units /ml) } \\
\text { (secondary antibody only) }\end{array}$} \\
\hline 50 & 3.7 & 55.9 & 1.5 & 37.8 \\
\hline
\end{tabular}

2 astrocytes was 26.1 and the MFI of Ia-positive cells in this sample was 109.4 .

Result from flow cytometric analysis of the microglial population is also in good agreement with the microscopic examination (Table 2). $80 \%$ of ameboid microglia became Ia-positive in the presence of IFN- $\gamma$. The MFI of this population approaches that of type 1 astrocytes. In both microscopic examination and flow cytometric analysis, there were a small number $(2 \%)$ of $\mathrm{Ia}^{+}$ cells in untreated cultures. Since the number is small, it is difficult to definitively conclude that a few microglia are $\mathrm{Ia}^{+}$in the absence of IFN- $\gamma$ induction.

\section{Discussion}

A number of studies have shown that rodent and human cultured astrocytes expressed Ia antigens after treatment with IFN- $\gamma$ (Hirsch et al., 1983; Wong et al., 1984; Fierz et al., 1985; Pulver et al., 1987; Mauerhoff et al., 1988). In these various reports, astrocytes were isolated by slightly different methods; however, the astrocytic marker GFAP was generally used to identify the astrocytes. Recent in vitro and in vivo studies have revealed that astrocytes constitute a heterogeneous population and subtypes of astrocytes can be differentiated by the expression of surface markers, morphology, and in situ location. Massa et al. (1987) identified Ia-positive astrocytes as type 1 astrocytes using the antibody Ran-2. The astrocytes used in most other reports also appear to be type 1 astrocytes judging from the separation methods used to prepare these cultures. To date, Ia antigen expression on type 2 astrocytes has not been extensively studied.

In this report we separated flat astrocytes and process-bearing cells from mixed glial cell cultures according to the method of McCarthy and de Vellis $(1978,1980)$. Highly purified type 1 astrocytes were prepared from subcultures of flat cells. Our findings of Ia antigen expression on type 1 astrocytes from Lewis rats are similar to those of previous reports (Massa et al., 1987; Frohman et al., 1988), i.e. Ia antigens were readily detected on type 1 astrocytes after treatment with IFN- $\gamma$.

For the enrichment and isolation of type 2 astrocytes, process-bearing glial cells were maintained in serum-supplemented media. Approximately $80 \%$ of the total cells became positive for the astrocyte marker, GFAP, after 5 days of subculture in this milieu. This is similar to values observed by others (Goldman et al., 1986; Ingraham and McCarthy, 1988). Type 2 astrocytes were characterized by staining with the monoclonal antibodies against GD3 and A2B5. Using these markers in double-immunofluorescence studies, we were able to show that only a small number of cells with process-bearing morphology are $\mathrm{Ia}^{+} / \mathrm{GFAP}^{+}, \mathrm{Ia}^{+} / \mathrm{GD}^{+}$, and $\mathrm{Ia}^{+} / \mathrm{A} 2 \mathrm{~B} 5^{+}$.

Both immunofluorescent microscopic studies and flow cytometric studies show that type 1 astrocytes express higher levels of Ia on a per cell basis, and that more type 1 astrocytes were induced to express Ia. Since both types of astrocytes were grown under the same condition (BME-10\% FCS), the difference of Ia induction could not be attributed to different in vitro culturing media. The implication of this result is that type 1 astrocytes may play a more important role in Ia-related, immune-mediated brain lesions since the quantity of Ia directly influences the immune response (Lechler et al., 1985). This contention is supported by in vivo findings where vast numbers 
of $\mathrm{HLA}-\mathrm{DR}^{+}$reactive astrocytes have been observed within gliosis around abscesses and metastases (Frank et al., 1986). These cells are likely type 1 astrocytes because gliosis appears to be formed mainly by type 1 astrocytes (Miller et al., 1986). Nevertheless, our finding that a small number of type 2 astrocytes express Ia antigens is also important due to the location of these cells in the white matter. These cells may play a role in immune-mediated diseases involving the white matter. It would be of future interest to determine Ia expression on subpopulations of astrocytes during normal and disease states.

During the preparation of this manuscript, Calder et al. (1988) have shown that IFN- $\gamma$ induced Ia on approximately $40 \%$ of type 2 astrocytes from 7-day-old rat optic nerve. The difference in the degree of Ia induction on type 2 astrocytes from optic nerve (their study) and cerebral cortex (our study) is of interest and may be due to different tissue origins.

We also studied microglia which were identified as ameboid microglia by morphology, the expression of CR3 complement receptor, expression of $\mathrm{Fc}$ receptor and the absence of GFAP. The results confirmed the previous observation that microglia express Ia upon IFN- $\gamma$ treatment. Interestingly, nearly all of the microglia express Ia in the presence of IFN- $\gamma$, while fewer type 1 astrocytes express the antigen. Thus the order of Ia levels in these glial populations is: microglia $>$ type 1 astrocytes $\gg$ type 2 astrocytes. The high percent of $\mathrm{Ia}^{+}$microglia may be directly related to the observation that $\mathrm{Ia}^{+}$microglia but not $\mathrm{Ia}^{+}$astrocytes have been found in a wide variety of neurologic disease states (McGeer et al., 1988b).

In conclusion, it appears that both astrocytes and microglia can be induced to express Ia while oligodendrocytes are unable to express Ia in vitro. On subtype of astrocytes, type 1 astrocytes are more inducible than type 2 astrocytes. Microglia and astrocytes may represent the initial trigger for intracerebral $\mathrm{T}$ cell activation and dictate the development of disease. However, the exact physiologic roles of different Ia expressing glial subpopulations are not clear yet. These cells may play different immunological roles and may be regulated by different mechanisms. Further investigation of Ia induction on each subtype of astro- cytes and microglia is important to understand their function in immune-mediated disease processes within the central nervous system.

\section{Acknowledgements}

We thank Dr. Ken McCarthy for his assistance and helpful discussions and Ms. Jane Radford for preparation of the manuscript.

This work was supported by a grant from the National Multiple Sclerosis Society, U.S.A.

\section{References}

Calder, V.L., Wolswijk, G. and Noble, M. (1988) The differentiation of $\mathrm{O}-2 \mathrm{~A}$ progenitor cells into oligodendrocytes is associated with a loss of inducibility of Ia antigens. Eur. J. Immunol. 18, 1195-1201.

de Tribolet, N., Hamou, M.F., Mach, J.-P., Carrel, S. and Schreyer, M. (1984) Demonstration of HLA-DR antigens in normal human brain. J. Neurol. Neurosurg. Psychiatry $47,417-418$.

Eisenbarth, G.S., Walsh, F.S. and Nierenberg, M. (1979) Monoclonal antibody to a plasma membrane antigen of neurons. Proc. Natl. Acad. Sci. U.S.A. 76, 4913-4917.

Fierz, W., Endler, B., Reske, K., Wekerle, H. and Fontana, A. (1985) Astrocytes as antigen-presenting cells. I. induction of Ia antigen expression on astrocytes by $\mathrm{T}$ cells via immune interferon and its effect on antigen presentation. $J$. Immunol. 134, 3785-3793.

Fontana, A., Fierz, W. and Wekerle, H. (1984) Astrocytes present myelin basic protein to encephalitogenic T-cell lines. Nature 307, 273-276.

Frank, E., Pulver, M. and de Tribolet, N. (1986) Expression of class II major histocompatibility antigens on reactive astrocytes and endothelial cells within the gliosis surrounding metastases and abscesses. J. Neuroimmunol. 12, 29-36.

Frei, K., Siepl, C., Groscurth, P., Bodmer, S., Schwerdel, C. and Fontana, A. (1987) Antigen presentation and tumor cytotoxicity by interferon- $\gamma$ treated microglial cells. Eur. J. Immunol. 17, 1271-1278.

Frohman, E.M., Vayuvegula, B., Gupta, S. and van der Noort, S. (1988) Norepinephrine inhibits $\gamma$-interferon-induced major histocompatibility class II (Ia) antigen expression on cultured astrocytes via $\beta_{2}$-adrenergic signal transduction mechanism. Proc. Natl. Acad. Sci. U.S.A. 85, 1292-1296.

Giulian, D. and Baker, T.J. (1986) Characterization of ameboid microglia isolated from developing mammalian brain. J. Neurosci. 6, 2163-2178.

Goldman, J.E., Geier, S.S. and Hirano, M. (1986) Differentiation of astrocytes and oligodendrocytes from germinal matrix cells in primary culture. J. Neurosci. 6, 52-60.

Hauser, S.L., Bhan, A.K., Gilles, F.H., Hoban, C.J., Reinherz, 
E.L., Schlossman, S.F. and Weiner, H.L. (1983) Immunohistochemical staining of human brain with monoclonal antibodies that identify lymphocytes, monocytes and the Ia antigen. J. Neuroimmunol. 5, 197-205.

Hayes, G.M., Woodroffe, M.N. and Cuzner, M.L. (1987) Microglia are the major cell type expressing MHC class II in human white matter. J. Neurol. Sci. 80, 25-37.

Hayes, G.M., Woodroofe, M.N. and Cuzner, M.L. (1988) Characterization of microglia isolated from adult human and rat brain. J. Neuroimmunol. 19, 177-189.

Hirsch, M.R., Wietzerbin, J., Pierres, M. and Goridis, C. (1983) Expression of Ia antigens by cultured astrocytes treated with interferon- $\gamma$. Neurosci. Lett. 41, 199-204.

Hofman, F.M., von Hanwehr, R.I., Dinarello, C.A., Mizel, S.B., Hinton, D. and Merrill, J.E. (1986) Immunoregulatory molecules and IL-2 receptors identified in multiple sclerosis brain. J. Immunol. 136, 3239-3245.

Ingraham, C.A. and McCarthy, K.D. (1988) Plasticity of process-bearing glial cell cultured from neonatal rat cerebral cortical tissue. J. Neurosci. 9, 63-69.

Lechler, R.I., Norcross, M.A. and Germain, R.N. (1985) Qualitative and quantitative studies of antigen-presenting cell function by using I-A expressing $\mathrm{L}$ cells. J. Immunol. 135, 2914-2922.

Massa, P.T., ter Meulen, V. and Fontana, A. (1987) Hyperinducibility of Ia antigen on astrocytes correlates with strainspecific susceptibility to experimental autoimmune encephalomyelitis. Proc. Natl. Acad. Sci. U.S.A. 84, 4219-4223.

Mauerhoff, T., Pujol-Borrell, R., Mirakian, K. and Bottazzo, G.F. (1988) Differential expression and regulation of major histocompatibility complex (MHC) products in neural and glial cells of the human fetal brain. J. Neuroimmunol. 18, 271-289.

McCarthy, K.D. and de Vellis, J. (1978) Alpha-adrenergic receptor modulation of $\beta$-adrenergic, adenosine and prostaglandin $E_{1}$ increased adenosine $3^{\prime}, 5^{\prime}$-cyclic monophosphate levels in primary culture of glia. J. Cyclic Nucleotide Res. 4, 15-26.

McCarthy, K.D. and de Vellis, J. (1980) Preparation of separate astroglial and oligodendroglial cell cultures from rat cerebral tissue. J. Cell Biol. 85, 890-902.

McGeer, P.L., Itagaki, S., Boyes, B.E. and McGeer, E.G. (1988a) Reactive microglia are positive for HLA-DR in the substantia nigra of Parkinson's and Alzheimer's disease brains. Neurology 38, 1285-1291.

McGeer, P.L., Itagaki, S. and McGeer, E.G. (1988b) Expression of the histocompatibility glycoprotein HLA-DR in neurological disease. Acta Neuropathol. 76, 550-557.

Miller, R.H. and Raff, M.C. (1984) Fibrous and protoplasmic astrocytes are biochemically and developmentally distinct. J. Neurosci. 4, 585-592.

Miller, R.H., Abney, E.R., David, S., French-Constant, C., Lindsay, R., Patel, R., Stone, J. and Raff, M.C. (1986) Is reactive gliosis a property of a distinct subpopulation of astrocytes? J. Neurosci. 6, 22-29.

Natali, P.G., De-Martini, C., Quaranta, V., Nicotra, M.R.,
Frezza, F., Pellegrino, M.A. and Ferrone, S. (1981) Expression of la-like antigens on normal human nonlymphoid tissues. Transplantation 31, 75-78.

Nixon, D.F., Ting, J.P.-Y. and Frelinger, J.A. (1982) Ia antigens on nonlymphoid tissues: their origins and functions. Immunol. Today 3, 339-342.

Pukel, C.S., Lloyd, K.O., Travassos, L.R., Dippold, W.G., Oettgen, H.F. and Old, L.J. (1982) GD3, a prominent ganglioside of human melanoma. J. Exp. Med. 155, 1133-1147.

Pulver, M., Carrel, S., Mach, J.P. and de Tribolet, N. (1987) Cultured human fetal astrocytes can be induced by interferon- $\gamma$ to express HLA-DR. J. Neuroimmunol. 14, 123-133.

Raff, M.C., Abney, E.R., Cohen, J., Lindsay, R. and Noble, M. (1983a) Two types of astrocytes in cultures of developing rat white matter differences in morphology, surface gangliosides, and growth characteristics. J. Neurosci. 3, 1289-1300.

Raff, M.C., Miller, R.H. and Noble, M. (1983b) A glial progenitor cell that develops in vitro into an astrocyte or an oligodendrocyte depending on culture medium. Nature 303 , 390-396.

Rodriguez, M., Pierce, M.L. and Howie, E.A. (1987) Immune response gene products (Ia antigens) on glial and endothelial cells in virus-induced demyelination. J. Immunol. 138, 3438-3442.

Sakai, K., Tabira, T., Endoh, M. and Steinman, L. (1986) Ia expression in chronic relapsing experimental allergic encephalomyelitis induced by long-term cultured $T$ cell lines in mice. Lab. Invest. 54, 345-352.

Suzumura, A., Silberberg, D.H. and Lisak, R.P. (1986) The expression of MHC antigens on oligodendrocytes: introduction of polymorphic H-2 expression by lymphokines. J. Neuroimmunol. 11, 179-190.

Suzumura, A., Mezitiz, S.G.E., Gonatas, N.K. and Silberberg, D.H. (1987) MHC antigen expression on bulk isolated macrophage-microglia from newborn mouse brain: induction of Ia antigen expression by $\gamma$-interferon. $J$. Neuroimmunol. 15, 263-278.

Takiguchi, M. and Frelinger, J.A. (1986) Induction of antigen presentation ability in purified cultures of astroglia by interferon- $\boldsymbol{\gamma}$. J. Mol. Cell. Immunol. 2, 269-280.

Ting, J.P.Y., Shigekawa, B.L., Linthicum, D.S., Weiner, L.P. and Frelinger, J.A. (1981) Expression and synthesis of murine immune response-associated (Ia) antigens by brain cells. Proc. Natl. Acad. Sci. U.S.A. 78, 3170-3174.

Traugott, U., Scheinberg, L.C. and Raine, C.S. (1985) On the presence of Ia-positive endothelial cells and astrocytes in multiple sclerosis lesions and its relevance to antigen presentation. J. Neuroimmunol. 8, 1-14.

Wekerle, H., Linington, C., Lassmann, H. and Meyermann, R. (1986) Cellular immune reactivity within the CNS. Trends Neurosci. 9, 271-277.

Wong, G.M.W., Bartlett, P.F., Clark-Lewis, I., Battye, F. and Schrader, J.W. (1984) Inducible expression of $\mathbf{H}-2$ and Ia antigens on brain cells. Nature $310,688-691$. 